\title{
¿Está el radiólogo expuesto a conflictos éticos en su práctica diaria?
}

Cristián García

Comité de ética de la Sochradi, Universidad Católica de Chile.

\section{La respuesta es sí.}

Los médicos radiólogos, al igual que el resto de los médicos, podemos estar expuestos a dilemas relacionados con la ética y el profesionalismo médico en nuestra práctica diaria, muchos de los cuales podemos no tener conocimiento alguno. Sin embargo, los desafíos éticos que enfrentamos en la práctica clínica son a menudo diferentes de aquellos a los cuales se enfrentan otros médicos, porque la naturaleza de la interacción médico-paciente del radiólogo es diferente a la de otras especialidades.

De esta manera, como médicos radiólogos estamos también expuestos a procesos judiciales por mala práctica o negligencia, en especial basados en lo que ha sido estipulado en la Ley de Derechos y Deberes del paciente, promulgada en nuestro país el año 2012.

Los cuatro principios éticos fundamentales y básicos en la relación médico-paciente son: la autonomía; la beneficencia; la no maleficencia y la justicia; y junto con ellos, el respeto a la intimidad, la confidencialidad (secreto médico) y la veracidad, también básicos en la relación con el enfermo y son todos necesarios en la práctica de la radiología.

Eventuales conflictos éticos, como aquellos relacionados con el desarrollo tecnológico (uso indiscriminado de los métodos de imágenes, transmisión de imágenes y lectura a distancia), la relación médicopaciente, y los derechos y deberes de los pacientes (consentimiento informado, autonomía, privacidad, intimidad, secreto médico, confidencialidad, pudor, dignidad) pueden ocurrir en nuestra especialidad. Los avances tecnológicos y la deshumanización de la medicina afectan especialmente a especialidades como la radiología.

Complementariamente, las habilidades de comunicación y relaciones interpersonales permiten mejorar la calidad de la atención médica, la satisfacción del paciente, los resultados y la confianza del paciente en su médico. Estas habilidades son fundamentales para fomentar y mejorar significativamente la interacción de nuestros radiólogos y los pacientes que requieren de nuestra ayuda. El radiólogo debe formar parte activa del equipo médico y participar en el diagnóstico y tratamiento de nuestros pacientes.

Algunos de los estudios de imágenes pueden no estar indicados, incluso algunos pueden significar un riesgo para el paciente o un gasto innecesario que muchas veces no podrá solventar. En esto, hay una responsabilidad ética compartida del radiólogo, de los clínicos y de las Instituciones de salud.

Por otro lado, la llamada medicina defensiva, donde la indicación de tratamientos, exámenes y procedimientos persigue proteger al médico de la crítica o de una eventual demanda, sin duda ha sido importante en el aumento explosivo del número de solicitudes de estudios de imágenes.

Como ha sido enfatizado en entidades y sociedades internacionales, debe hacerse énfasis en el estudio y la enseñanza de la ética y el profesionalismo en radiología en estudiantes de medicina, residentes de radiología y profesionales de la especialidad, a través de los Programas de Residencia en Radiología y la educación continua de los radiólogos.

El objetivo final es mejorar la atención y la seguridad de los pacientes, mejorar la responsabilidad social en la atención médica y la práctica dentro de la comunidad radiológica. Todas las disciplinas médicas, por muy tecnológicamente sofisticadas o alejadas del contacto directo con los pacientes, necesitan poner primero el cuidado de los seres humanos

En resumen, la ética médica es un campo enorme, con múltiples conceptos y principios que tocan a todas las especialidades médicas, incluida la radiología.

Como Comité de Ética de la Sociedad Chilena de Radiología, es nuestra intención publicar una serie de artículos acerca de este tema en nuestra Revista, tratando de sensibilizar a todos los médicos que practicamos día a día la radiología y nos vemos 
enfrentados a dilemas éticos, muchos de los cuales no tenemos conocimiento alguno.

Se acompañan referencias que pueden ser de interés.

\section{Bibiografìa}

1. American Medical Association. AMA Code of Medical Ethics. https://www.ama-assn.org/delivering-care/ ama-code-medical-ethics.

Consultado 2 Julio 2017.

2. Armstrong JD. Morality, Ethics, and Radiologists' Responsibilities. AJR 1999; 173: 279-284.

3. Berlin L. Medicolegal - Malpractice and Ethical Issues in Radiology. Am J Roentgenol 2016; 207: W19.

4. Berlin L. To whom is the radiologist responsible? AJR 2012; 198: [web]W191

5. Berlin L. Malpractice Issues in Radiology. Perceptual Errors. Am J Roentgenol 1996; 167: 587-90.

6. Chawla A, Gunderman RB. Defensive Medicine: Prevalence, Implications, and Recommendations. Acad Radiol 2008; 15: 948-949.

7. Cook K. Medicolegal considerations in the implementation of a PACS web application. J Digit Imaging 2002; 15 Suppl 1: 240-241.

8. Cunningham N, Reid L, MacSwain S, Clarke SR. Health Policy and Practice / Santé: Politique et pratique medicale. Ethics in Radiology: Wait Lists Queue Jumping. Canadian Association of Radiologists Journal 2013;
64: 170-175.

9. Duszak R Jr, Muroff LR. Measuring and managing productivity. Part 2. Beyond the clinical numbers. J Am Coll Radiol 2010; 7: 482-489.

10. Gunderman RB. Why is ethics needed in the radiology curriculum? Acad Radiol 2001; 1: 82-85.

11. Gunderman RB. Ethics and professionalism: The patient's perspective. J Am Coll Radiol 2008; 5: 612615.

12. Gunderman RB, Brown BP. Excellence and Professionalism in Radiology. Am J Roentgenol 2013; 200: W557-W559.

13. Gunderman RB. Images of the imager: The essential role of ethics in the future of radiology. Acad Radiol 1999; 6:148-155 7.

14. Kelly AM, Mullan PB, Gruppen LD. The Evolution of Professionalism in Medicine and Radiology. Acad Radiol 2016;23: 531-536.

15. Lau PW, Illes J. The Gray Zones of Privatized Imaging. The American Journal of Bioethics 2009; 9: 21-22.

16. Professionalism. A key element of being a doctor. A core competency of the American Board of Radiology. http://www.rsna.org/Professionalism/ Consultado 2 Julio 2017.

17. Raymond J, Trop I. The Practice of Ethics in the Era of Evidence-based Radiology. Radiology 2007; 244: 643-649.

18. White $\mathrm{P}$. Legal issues in teleradiology-distant thoughts. Br J Radiol 2002; 75: 201-206.

García C., ¿Está el radiólogo expuesto a conflictos éticos en su práctica diaria? Rev Chil Radiol 2017; 23(2): 46-47 Correspondencia: Cristián García. / cgarcíab@uc.cl

Trabajo recepcionado el 09 de junio de 2017. Aceptado para publicación el 08 de julio de 2017. 